\title{
Phenomenological model of an open-type geothermal system on the basis of oil-and-gas well
}

\author{
Mykhailo Fyk ${ }^{1 *}$, and Volodymyr Biletskyi ${ }^{1}$ \\ ${ }^{1}$ National Technical University "Kharkiv Polytechnic Institute", Institute of Chemical Technology \\ and Engineering, 2 Kyrpychova St., 61002 Kharkiv, Ukraine
}

\begin{abstract}
This paper relates to mining-well technologies. A theoretical and methodological approach is proposed to modeling geothermal well systems, which includes the development of: principal technological scheme of a geothermal system; schemes of transformation and movement of energy and a heat-transfer medium; the geothermal system phenomenological model; analysis of subprocesses and obtaining their mathematical models and, on this basis, the mathematical model of the geothermal model as a whole. An example of an advanced open-type geothermal well system is studied, which is based on the oil-and-gas well with one loop of circulation and the parallel connection of heat pumps at characteristic points of the system. The subprocesses of the developed phenomenological model are analysed and the characteristic features of their mathematical description are revealed; in particular, it is substantiated that the redistribution of heat power entering from a fluidsaturated bed is substantially dependent on the lateral wellbore geometry. Another important feature is to model the downhole heat pump and the modes in the scheme as a whole, which is based on the mass flow rate of a heat-transfer medium in its circulation loop. A generalized formula is presented for the heat power of the analysed advanced geothermal well system.
\end{abstract}

\section{Introduction}

This work is devoted to the research and methodological approaches development for modeling open geothermal mining-well systems of depleted and existing oil-and-gas fields $[1-12]$. Usually, on the basis of one oil-and-gas well (which belongs to the geothermal fund), a geothermal system is constructed using heat exchange process between the mine rock and a heat-transfer medium. As a heat-transfer medium, both a natural fluid or artificial liquid-gas mixtures (propane, butane, etc. [4]) can be used. Heat exchange of a heat-transfer medium upflow occurs in the productive bed, bottom-hole zone, bottom hole $[4-5]$ and in the underground columns $[6,9]$. The heated heat-transfer medium rises to the surface, where it transfers heat to the target system (for example, heating system). Heat exchange of a heat-transfer medium downflow occurs in the injection string and in the bed

\footnotetext{
*Corresponding author: mfyk@ukr.net
} 
injection zone.

Fig. 1 shows a structure diagram of an open geothermal single-well system with lateral wellbores on the production line, which was developed on the basis of works $[3,6,8]$.

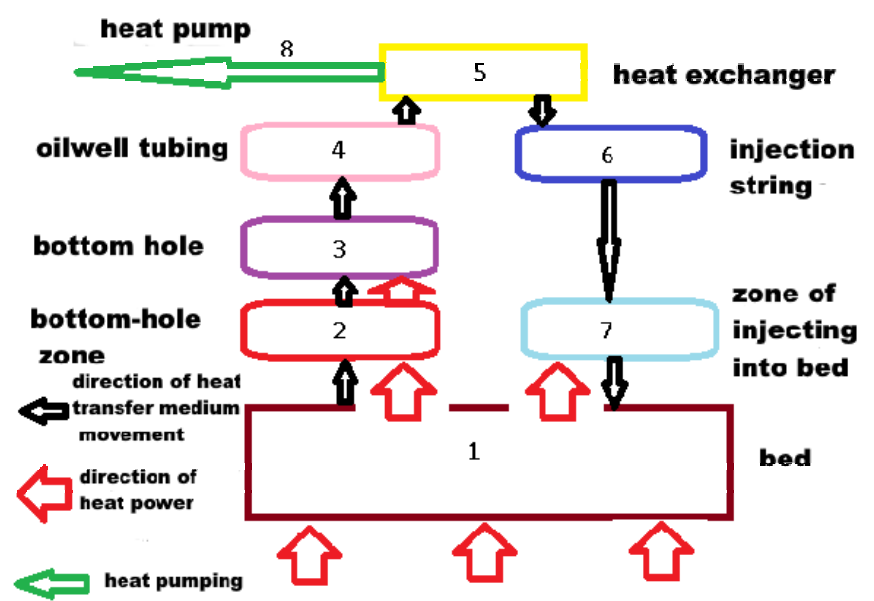

Fig. 1. The structure diagram of modern open geothermal single-well systems with lateral wellbores on the production line and a single-stage heat pump.

The heat-transfer medium, heated to bed temperature, is taken from the bed 1 , and with a temperature close to this, it enters to the heat exchanger 5 . Heat is pumped in one stage by the wellhead heat pump 8 . The bottom hole of the injection well is theoretically ignored, since a heat-transfer medium with a low temperature (cooling is carried out in the heat exchanger 5) after passing through the injection string 6 , is to be pumped into the injection zone 7 and bed 1 without additional heat-engineering and hydraulic losses. The injection string 6 is additionally heat-insulated so that on the way from the heat exchanger to the bed, the maximum temperature difference "bed - heat-transfer medium" is preserved. The heat of the bedding geological structure as an energy donor is supplied to the bed 1 , the nearwellbore zone 2 and the injection zone 7 . Theoretically, existing scientific methodologies take into account heating (heat input from the bed) of the bottom hole in oilwell tubing section $3[10,13]$.

Geothermal system (Fig. 1) can be developed by adding several circulation loops and using parallel (sequential) connection of heat pumps. The most promising is the use of a one-loop system with the parallel connection of heat pumps between the main stages of heat exchange process.

Methods. A universal research and methodological approach to the description and analysis of such systems can be a phenomenological model of the process. This is a scheme that reflects the sequence and interconnection of all elementary physical and other processes (subprocesses) occurring at each stage of the technological process, in particular, in mining complex - during mining and processing of minerals [14-18]. Therefore, it is expedient to study the phenomenological methodology tools implementation using the example of a certain geothermal system with the purpose of obtaining its mathematical model.

The purpose of this work is to develop a theoretical and methodological approach to modeling geothermal mining-well systems using a phenomenological model of an advanced open-type geothermal well system based on the oil-and-gas well with one circulation loop and parallel connection of heat pumps at characteristic points of the system.

To achieve this purpose, the following tasks should be performed: 1 . Development of a principal technological scheme of an advanced one-loop geothermal mining-well system 
with the parallel connection of heat pumps between the main stages of heat exchange process. 2. Development of a phenomenological model that corresponds to the indicated technological scheme. 3. The subprocesses analysis of the phenomenological model and revealing the characteristic features of their mathematical description.

\section{Results and discussion}

\subsection{Principal technological scheme development of an advanced one-loop geothermal system}

To exploit the geothermal system of the above type, it is necessary to disclose the well into the bed for a sufficient heat-transfer medium flow in the filtration zone near the bottom hole of the injection and production lines, in the filtration zone of a bed, in the injection string and lifting well, in the cooling heat exchanger of the heat pump (Fig. 1). The heated heattransfer medium is lifted up (for depths less than $3 \mathrm{~km}$ ) along the heat-insulated tubing 4 , and the cooled heat-transfer medium after the heat exchanger 5 is injected into the bed 1 through the string without heat insulation 6 (see Fig. 1). The development of larger depths and wells with a limited heat flow rate for geothermal energy requires to take into account increased heat echange along the strings, along lateral wellbores in open geothermal systems. It is expedient also to partially or completely insulate pipes on the injection line or take other measures to optimize the geothermal system efficiency as a whole.

The structure diagram shown in Fig. 1 of an open geothermal single-well system does not take into account the fact that, in principle, two-stage heating of a heat-transfer medium can be realized, which is possible first in the borehole annulus 6 and only after that in the zone of a bed 1 and straight near the bottom hole. It would be possible to implement a twostage heating process, if to use more than one heat pump (on the surface near the wellhead), hence, it is expedient to set at least two of them. In addition, a heat-transfer medium along the injection string should pass in the maximized contact with the near-borehole space, entering through this space (outside the heat-insulated oilwell tubing). The last process is possible if to take into account the capabilities of modern magnetic coolers and bottom-hole heat exchangers, which are proposed by the authors to implement into the circuit practice at the bottom hole and in the lateral wellbores of the well bottom hole network system. The basis to create an improved technological scheme and the corresponding phenomenological model of an open geothermal system for the oil-and-gas well was an analysis of experimental research into significant capabilities of extracting thermal energy in the nearborehole zone of the oil-and-gas wells, which are assigned to the heat production and assessed in the range of $1-3 \mathrm{MW}$ at depths $3-5 \mathrm{~km}$ [11-13]. The latter parameter is comparable with the potential $9-15 \mathrm{MW}$ of heat production from depleted oil-and-gas beds at the same depths and under the same conditions [16 - 17].

To increase the efficiency of heat transfer between the main stages of the geothermal system heat exchange process, it is expedient to arrange the heat pumps so that they separate the heat exchange zones in the bed and in the strings. The developed technological scheme of this principle implementation is shown in Fig. 2.

Fig. 2 shows that the main technological scheme blocks are located on one closed loop according to the path of a heat-transfer medium circulation (directions are shown by black arrows). Blocks $1-8$ are flow-through for a heat-transfer medium and each of them causes heat exchange processes with directions in accordance with the regime temperature distribution and circulation direction. In the scheme, the red arrows show the direction of heat inflow to the loop blocks. In particular, in the bed (block 1), bottom-hole zones (blocks 2, 8), bottom holes, downward and upward injection lines (blocks 3 and 7), discharge column (block 6), there is a heat inflow from adjacent mine rocks to a heat-transfer 
medium. In the oilwell tubing (block 4), the heat is directed towards the mine rock, and in the heat exchanger (block 5) and in the bottom hole of injection (block 7), heat is taken by the heat pumps and directed towards the consumer of the thermal energy (the thermal energy pumping by heat pumps is shown by green arrows).

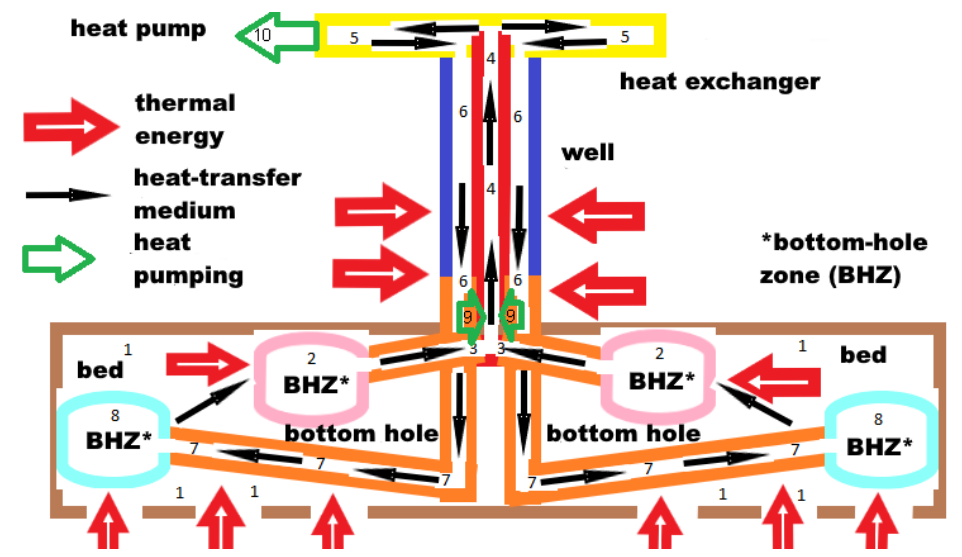

Fig. 2. Technological scheme of the open geothermal system based on an oil-and-gas well with lateral wellbores and parallel connection of heat pumps.

\subsection{Phenomenological model development}

Phenomenological model development is performed in two stages: 1) development of a scheme of transformation and movement of energy and a heat-transfer medium; 2) development of the geothermal system phenomenological model.

According to the technological scheme shown in Fig. 2, a scheme of transformation and movement of energy and a heat-transfer medium has been developed (Fig. 3). In this model, the output values of each previous set of subprocesses of the technological block are the input for the next technological block in the direction of the arrows shown in five different colors. A certain process as a set of subprocesses in relation to the energy of two types (thermal and gas-hydraulic) and matter (heat-transfer medium) is considered as an element of scheme of transformation and movement of energy and a heat-transfer medium. Figure 3 shows the three main physical processes of the studied geothermal system, which occur in a conditionally divided into separate elements (processes) 1-10 models: heat transfer (indicated by circles upon availability), mass transfer (indicated by squares upon availability) and conversion of mechanical energy into potential pressure energy (indicated by triangles upon availability). Undoubtedly, the last subprocess takes place in the geothermal system - the inflow and loss of gas-hydraulic energy (potential pressure energy), but it is shown in Fig. 3 only for active elements in order to simplify visualization. This subprocess is positive (energy increase) only in blocks 5,9-10, and in the rest blocks there is a process of gas-hydraulic energy loss and partial conversion to thermal energy. The processes (elements) blocks in Fig. 3 are numbered in accordance with the technological scheme in Fig. 2, since each technological block of the scheme is an element of the model of movement and conversion (transformation) of energy and matter. Indeed, from Fig. 3 it follows that in each indicated element physical processes of heat and energy transfer and/or mass transfer occurs, that is, a set of the three main subprocesses mentioned above. Therefore, it is not possible to combine several technological blocks (see Fig. 2) into one model element (see Fig. 3). It can be seen from Fig. 3 that mass transfer takes place in the $1-8$ model elements, and heat transfer occurs in the $1-3$ and 5-10 elements. Passive 
loss of potential pressure energy occurs in the $1-4$ and $6-8$ elements. Potential gashydraulic pressure energy is generated only by converting the mechanical energy of the pump shaft in the active element 5, where a circulation pump (active element of the hydraulic system) is usually set. The direction of movement of heat, mechanical energy and the mass transfer are indicated on the model of transformation and movement of energy and matter by one-sided arrows. At that, red indicates the heat inflow from the rock massifs into the model element, the blue arrow indicates the heat outflow from the element to the rock massifs or to the consumer, the green arrow indicates heat transfer from one element to another element of the phenomenological model, the black arrow indicates the mass transfer from one model element to another element, and the yellow arrow indicates the conversion of mechanical energy into potential pressure energy.

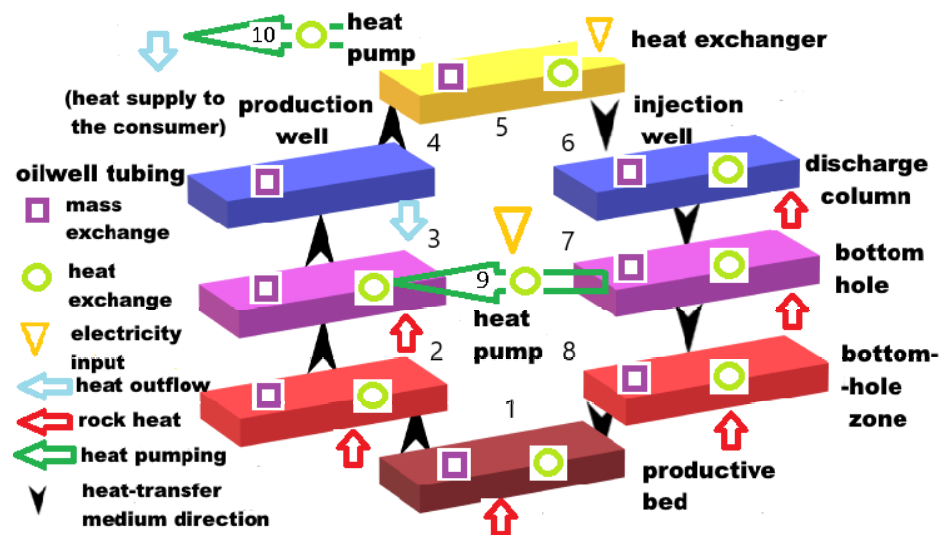

Fig. 3. Scheme of transformation and movement of energy and a heat-transfer medium of the geothermal system based on an oil-and-gas well with lateral wellbores and working in parallel bottom-hole and wellhead heat pumps.

The temperature decreases from element 2 to 4 (Fig. 3), since the bottom-hole zone 3 is characterized by an active throttling effect, and the oilwell tubing 4 partially loses heat (not intensively). This last fact explains that the heat exchange process is not shown on the model for element 4 . The temperature gradually increases from element 7 to element 3 (in the heat-transfer medium direction, as indicated by black arrows). In the discharge (injection string) column 6 , the temperature of a heat-transfer medium increases, and in the element 7 decreases by the heat pump 9 .

The pressures are distributed in the circulation loop of a heat-transfer medium in accordance with the mechanical energy inflow from the pump shaft, hydrostatic pressure drop (in regard with the weight of a heat-transfer medium in the columns) and hydraulic losses in each of the model elements (Fig. 3). The maximum pressure drops are undoubtedly formed in the heat exchanger 5 , columns 4 and 6 , and the bed 1 .

The developed scheme of transformation and movement of energy and a heat-transfer medium in the geothermal system (Fig. 3) simplifies obtaining of a phenomenological model (Fig. 4).

The phenomenological model contains three main subtypes of subprocesses - heat and mass transfer, heat transfer, and thermal-mechanical transformation.

Subprocesses 1.1 and 1.2 reflect the thermal energy inflow into the system.

Subprocesses 2.1, 2.2, 2.3 are heat exchange processes between a heat-transfer medium and a fluid-saturated bed.

Subprocesses 3.1, 3.2, 3.3 - the processes of heat redistribution, which is collected in the bed along the bed zone and bottom-hole zone. 
Subprocesses $4.1-4.8$ - circulation processes of the heat-transfer medium, heat and mass transfer.

Subprocesses 5.1 - 5.3 - processes of heat and mass transfer and conversion of the thermal energy into mechanical and hydraulic for the operation of the circulation pump and heat pumps.

Subprocess 6 - the output of thermal energy to the consumer.

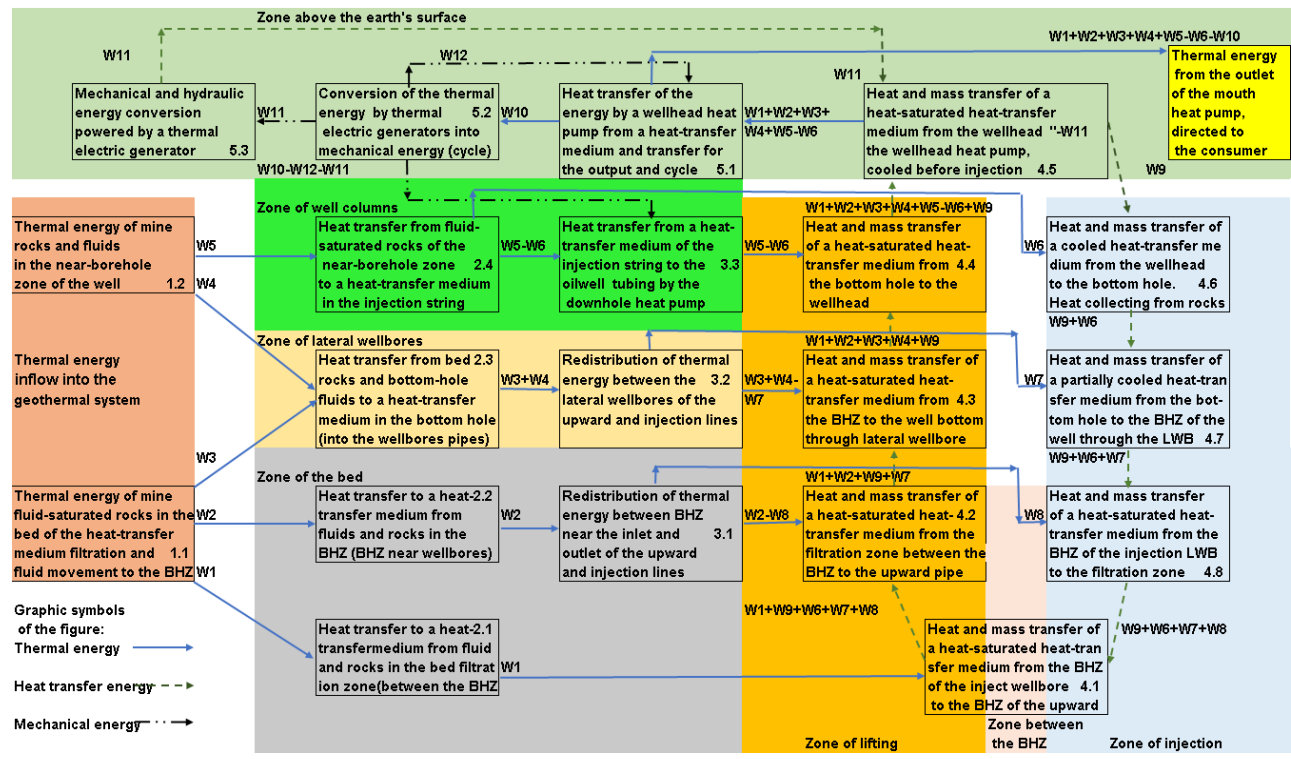

Fig. 4. Phenomenological model of an open-type geothermal system based on the oil-and-gas well when using two heat pumps at the bottom hole and wellhead, as well as one circulation pump.

The output parameters of subprocesses and the global output parameter of the model are the parameters of the thermal energy. The developed phenomenological model is the basis for obtaining a mathematical model of each of the subprocesses and the geothermal system as a whole. Moreover, it presents a concept of the thermal energy movement from the inlet to the outlet of an open-type geothermal system on the basis of the oil-and-gas well. In addition, each specific phenomenological model clearly corresponds to the technological scheme.

In the studied example, a technological scheme is proposed and a corresponding phenomenological model is developed for the case if there is a cycle of the reverse use of the thermal energy fraction of near-borehole rocks and fluid-saturated rocks for the 3 pumps drive (two heat pumps at the bottom hole and wellhead and one circulation pump). The energy is introduced into the system from the pumps in two subzones, where there is a technological need to activate heat transfer and support the mass transfer process. Thermal energy inflows from the mine rocks of a bed and lateral mine rocks near the columns, then, it is taken by the heat pump near the wellhead. In the developed model, the thermal energy loss in the oilwell tubing is ignored, since modern columns are equipped with high-quality heat insulation.

In subprocesses $4.1-4.8$, an increase or decrease in the thermal energy of a heattransfer medium occurs, which is characterized by its temperature $T$. Changes in temperature (obtaining or loss of the thermal energy) occur during the transition between zones that are shown vertically and horizontally. Vertically, four such zones are shown: above the earth's surface, a column, lateral wellbores and a bed with bottom-hole zone 
(BHZ). Horizontally, there are three such zones - upward with lifting from the bottom hole, intermediate with the $\mathrm{BHZ}$ and the bed in the vicinity of the BHZ, as well as injection zone with discharge to the bottom hole.

The developed phenomenological model (Fig. 4) can be considered as universal when exploiting only one horizon at a certain depth. However, when disclosing an oil-and-gas well at the depths of several layers of geothermal horizons, the number of downhole heat pumps and zones of vertical differentiation should be increased by the number of additionally developed horizons. This is necessary to reduce the thermal potential of the circulating heat-transfer medium to a minimum value before it inflows into the bed. In accordance with this, the configuration of the phenomenological model is also transformed.

\subsection{Analysis of the phenomenological model subprocesses}

Denote by $W, \mathrm{~J} / \mathrm{s}$ - the total power of thermal, hydraulic and mechanical energy. The total heat power $W_{\text {sum }}$ enters from the bed and near-borehole fluid-saturated rocks:

$$
W_{\text {sum }}=W_{1}+W_{2}+W_{3}+W_{4}+W_{5} .
$$

Hydraulic losses in the circulation loop (upward and downward flow) of a heat-transfer medium:

$$
W_{11}=W_{10}-W_{t n b}-W_{t n w},
$$

where $W_{12}=W_{t n w}$ is losses of mechanical power in the system for the drive of the wellhead heat pump, $W_{10}$ is total power losses for the drive of all pumps.

The heat-transfer medium enters to the injection line with power $W_{9}$. The overall energy balance of the studied geothermal system based on an oil-and-gas well is:

$$
W=W_{\text {sum }}-W_{10}-W_{6}=W_{1}+W_{2}+W_{3}+W_{4}+W_{5}-W_{6}-W_{10},
$$

where $W_{6}$ is heat losses in the underground part of the columns, which for the technological scheme (Fig. 2) occur mainly outside the injection string.

Additional designations: $W_{7}$ is heat power from the rocks, which enters into the lateral wellbore of the injection line, taking into account of hydraulic losses in this lateral wellbore. $W_{8}$ is heat power from the rocks, which enters into the $\mathrm{BHZ}$ of the injection line, taking into account the pressure losses in the BHZ.

It follows from formula $(1-3)$, as well as from the balanced equations and power values between subprocesses in Fig. 4 that the heat power $W$ comes to the consumer reduced relative to the total heat inflow from mine rocks by the sum of the hydraulic and thermal-mechanical losses of the system through the entire scheme as a whole.

The inflow of heat power $W_{\text {sum }}$ from subprocesses 1.1 and 1.2 to $2.1-2.3$ and the element-by-element redistribution of heat depends on the temperature distribution in the $\mathrm{BHZ}$ and in the lateral wellbores. Such an analysis is performed in [20-24] and can be used when implementing this technological scheme in production. The approach is based on the method of step-by-step reduction of a vector-parametric lattice cell with recalculation of parameter tables in a cycle. Subprocesses $4.1-4.8$ and 5.1-5.3 are described in detail in terms of their modeling in the works [25-28]. Thus, almost all of these subprocesses are well described by well-known mathematical and algorithmic methods [29-33]. The exceptions are the subprocesses of the line $3.1-3.3$, which have the phenomena of gravitational cases in the subprocesses 3.1-3.2 and the balancecompensating phenomenon in the subprocess 3.3, which are imposed on the thermal processes of the powers passage redistribution in the scheme.

For subprocesses 3.1 and 3.2, the systems of differential equations in vector-matrix form have been developed, which are similar and are substantiated by the "figure-eight" 
graph of the flow and energy scheme (Fig. 3):

$$
M_{q 1}=M_{q 2}
$$

where $M_{q 1}, M_{q 2}$ are mass flow rates for the downward and upward lateral wellbores;

$$
W_{2}+W_{3}+W_{4}=\lambda S_{c 1} / l_{\sigma 1} d S_{d 1} d T_{1}+\lambda S_{c 2} / l_{\sigma 1} S_{d 2} d T_{2}
$$

where $W_{2}, W_{3}, W_{4}$ are heat power obtained by lateral wellbores and BHZ; $\lambda$ is the average thermal conductivity of a heat-transfer medium; $l_{\sigma 1}, l_{\sigma 1}$ are characteristic heat exchange lengths; $S_{c}, S_{d}=S_{c} \sin (\alpha)$ area of convective-conductive heat exchange and area of thermal diffusion; $\alpha$ - angle of lateral wellbore inclination;

$$
P_{2} P_{1}=\rho Z R\left(T_{2}-T_{1}\right)+\rho g d H,
$$

where $P_{2}, P_{1}$ are average pressures of the injection and productive lateral wellbores; $T_{2}, T_{1}$ are average temperatures of lateral wellbores; $\rho, Z, R$ are density, compressibility and constant of a heat-transfer medium averaged over the overal heat exchange zone; $d H$ is elevation difference between midpoints of heat exchange centers.

$$
\begin{gathered}
W_{2}+W_{3}+W_{4}-W_{7}-W_{8}=W_{6} ; \\
P=\rho Z R T,
\end{gathered}
$$

where $P, \rho, Z, R, T$ are 3D matrices of distributed pressures, density, compressibility, constant, and temperature of a heat-transfer medium in a system with distributed parameters.

From the system of equations of mass, energy, movement, scheme balance of powers and state $(4-8)$, it can be seen that the redistribution of powers $W_{2}$ from outlet 2.2 and $W_{3}+W_{4}$ from outlet 2.3 depends on the lengths $l_{\sigma}$ and the angles of lateral wellbores inclination $\alpha$, elevation differences $d H$ between midpoints of the lateral wellbores (for 3.2) or the BHZ of the downward and upward lines (for 3.1).

Subprocess 3.3 is described by the system of equations $(4,6,8-10)$ for a graph with the geometric "H"-type topology on the column zone line (Fig. 3), where the parameter indices now correspond not to lateral wellbores with different depths, but to the oilwell tubing (index - 1) and injection (index - 2) column:

$$
W_{5}=M_{q 2} C_{p} d T-W_{6}-W_{4},
$$

where $W_{5}$ is heat power, which is obtained by a heat-transfer medium in the column area and is lifted to the surface (Fig.4); $W_{4}$ is heat power entering from the near-borehole zone to the bottom-hole lateral wellbores (overflow between the zones of the columns and lateral wellbores); $C_{p}$ is average heat capacity of a heat-transfer medium in the injection string; $d T$ is longitudinal gradient of a heat-transfer medium temperature, which takes place on the line from the wellhead to the bottom hole.

$$
\operatorname{COP}\left(W_{10}-W_{11}-W_{12}\right)=W_{5},
$$

where $C O P$ is downhole heat pump efficiency coefficient.

An analysis of the complete system of analytical dependences (1)-(10) using an example of a schematic-technological organization (Figs. 2 and 3) shows that a quantitative index of the power transfer $W_{5}$ from the bottom hole part of the injection line to the inlet of the upward flow into the oilwell tubing can be determined only on condition of a specific mass flow rate of a heat-transfer medium $M_{q}$. Consequently, the heat exchangers of the type "lateral wellbore - downhole heat pump" should be designed taking into account the entire range of mass flow rates during circulation. 


\section{Conclusions}

A theoretical and methodological approach is proposed to modeling geothermal miningwell systems, which includes the development of: principal technological scheme of a geothermal system; schemes of transformation and movement of energy and a heat-transfer medium; the geothermal system phenomenological model; analysis of subprocesses and obtaining their mathematical models and, on this basis, the mathematical model of the geothermal model as a whole. An example of an advanced open-type geothermal well system has been studied in detail, which is based on the oil-and-gas well with one circulation loop and the parallel connection of heat pumps at characteristic points of the system.

1. An advanced technological scheme of a geothermal mining-well system has been developed that takes into account two-stage parallel pumping of heat from the nearborehole space and the bed of an open geothermal single-well system, which has lateral wellbores of the bottom hole branching. At the same time, the possibility was taken into account of setting heat exchangers of the downhole heat pump on the network bottom hole system using the lateral wellbores lengths with individual bottom-hole zones.

2. A scheme of transformation and movement of energy and a heat-transfer medium, which corresponds to the indicated technological scheme, as well as a geothermal system phenomenological model have been developed.

3. The subprocesses of the phenomenological model have been analysed and the characteristic features of their mathematical description have been revealed; in particular, it has been substantiated that the redistribution of heat power entering from a fluid-saturated bed is substantially dependent on the lateral wellbore geometry. Another important feature is to model the downhole heat pump and the modes in the scheme as a whole, which is based on the mass flow rate of a heat-transfer medium in its circulation loop; a generalized formula is presented for the heat power of the analysed advanced geothermal well system.

This work was conducted within the project "Development of scientific bases for energy-efficient technologies of fluid development" (State registration No. 0120U100361).

\section{References}

1. Fyk, M., Biletskyi, V., \& Abbud, M. (2018). Resource evaluation of geothermal power plant under the conditions of carboniferous deposits usage in the Dnipro-Donetsk depression. E3S Web of Conferences, (60), 00006. https://doi.org/10.1051/e3sconf/20186000006

2. Pathak, V., Babadagli, T., Majorowicz, J.A., \& Unsworth, M.J. (2014). Evaluation of Engineered Geothermal Systems as a Heat Source for Oil Sands Production in Northern Alberta. Natural Resources Research, 23(2), 247-265. https://doi.org/10.1007/s11053-013-9218-4

3. Weydt, L.M., Heldmann, C.-D.J., Machel, H.G., \& Sass, I. (2018). From oil field to geothermal reservoir: assessment for geothermal utilization of two regionally extensive Devonian carbonate aquifers in Alberta, Canada. Solid Earth, (9), 953-983. https://doi.org/10.5194/se-9-953-2018

4. Fyk, M., Biletskyi, V., Ryshchenko, I., \& Abbood, M. (2019). Improving the geometric topology of geothermal heat exchangers in oil bore-holes. E3S Web of Conferences, (123), 01023. https://doi.org/10.1051/e3sconf/201912301023

5. Fyk, M., Biletskyi, V., Fyk, I., Bondarenko, V., \& Al-Sultan, M. (2019). Improvement of an engineering procedure for calculating the non-isothermal transportation of a gas-liquid mixture. Eastern-European Journal of Enterprise Technologies, 3(5(99), 51-60. https://doi.org/10.15587/1729-4061.2019.167198

6. Watson, S.M., Falcone, G., \& Westaway, R. (2020). Repurposing Hydrocarbon Wells for Geothermal Use in the UK: a Preliminary Resource Assessment. Proceedings World Geothermal Congress 2020. Reykjavik, Iceland. 
7. Fyk, M., Fyk, I., Biletsky, V., Oliynyk, M., Kovalchuk, Yu., Hnieushev, V., \& Shapchenko, Yu. (2018). Theoretical and applied aspects of using a thermal pump effect in gas pipeline systems. Eastern-European Journal of Enterprise Technologies, 1(8(91)), 39-48. Retrieved from https://doi.org/10.15587/1729-4061.2018.121667.

8. Vaganova, N. A., \& Filimonov, M. Y. (2019). Optimization of location of injection wells in an open geothermal system. Proceedings of the 45th International Conference on Application of Mathematics in Engineering and Economics (AMEE'19). https://doi.org/10.1063/1.5133554

9. Toth, A.N., Szucs, P., Pap, J., Nyikos, A., \& Fenerty, D.K. (2018). Converting Abandoned Hungarian Oil and Gas wells into Geothermal Sources. Proceedings, 43rd Workshop on Geothermal Reservoir Engineering. Stanford, California.

10. Tomaszewska, B., Sowiżdżał, A., \& Chmielowska, A. (2018). Selected technical aspects of well construction for geothermal energy utilization in Poland. Contemp. Trends. Geosci, 7(2), 188199. https://doi.org/10.2478/ctg-2018-0013

11. Sui, D., Wiktorski, E., Røksland, M., \& Basmoen, T.A. (2019). Review and investigations on geothermal energy extraction from abandoned petroleum wells. Journal of Petroleum Exploration and Production Technology, 9(2), 1135-1147. https://doi.org/10.1007/s13202-018-0535-3

12. Bondarenko, V., Kovalevs'ka, I., \& Ganushevych, K. (2014). Progressive technologies of coal, coalbed methane, and ores mining. London, United Kingdom: CRC Press, Taylor \& Francis Group. https://doi.org/10.1201/b17547

13. Nian, Y.L., \& Cheng, W.L. (2018). Evaluation of geothermal heating from abandoned oil wells. Energy, (142), 592-607. https://doi.org/10.1016/j.energy.2017.10.062

14. Biletsky, V., Molchanov, P., Sokur, M., Gayko, G., Savyk, V., Orlovskyy, V., Liakh, M., Yatsyshyn, T., \& Fursa, R. (2017). Research into the process of preparation of Ukrainian coal by the oil aggregation method. Eastern-European Journal of Enterprise Technologies, 3(5(87)), 4553. https://doi.org/10.15587/1729-4061.2017.104123

15. Biletskyi, V., Molchanov, P., Orlovskyy, V., \& Shpylovyi, L. (2017). Research into the mechanism of aggregate-forming objects contact with oil aggregation of finely-dispersed coal. Mining of Mineral Deposits, 11(4), 19-28. https://doi.org/10.15407/ mining11.04.019

16. Nalla, G., Shook, G. M., Mines, G. L., \& Bloomfield, K. K. (2005). Parametric sensivity study of operating and design variables in wellbore heat exchangers. Geothermics, 34(3), 330-346. https://doi.org/10.1016/j.geothermics.2005.02.001

17. Shendrik, O., Fyk, M., Biletskyi, V., Kryvulia, S., Donskyi, D., Alajmeen, A., \& Pokhylko, A. (2019). Energy-saving intensification of gas-condensate field production in the east of Ukraine using foaming reagents. Mining of Mineral Deposits, 13(2), 82-90. https://doi.org/10.33271/mining13.02.082

18. Li, F., Xu, T., Li, S., Feng, Bo, Jia, X., Feng, G., Zhu, H., \& Jiang, Z. (2019). Assessment of Energy Production in the Deep Carbonate Geothermal Reservoir by Wellbore-Reservoir Integrated Fluid and Heat Transport Modeling. Geofluids, 2019, 1-18. https://doi.org/10.1155/2019/8573182

19. Pivnyak, G., Bondarenko, V., \& Kovalevska, I. (Eds.). (2015). New Developments in Mining Engineering 2015. London, United Kingdom: CRC Press, Taylor \& Francis Group. https://doi.org/10.1201/b19901

20. Suárez-Arriaga, M.C. (2019). Thermodynamics of Deep Supercritical Geothermal Systems. IOP Conference Series: Earth and Environmental Science, (249), 012019. https://doi.org/10.1088/1755-1315/249/1/012019

21. Stefanović, V., Drobnjaković, B., \& Pavlović, S. (2019). Necessary measures and calculation for dimension of coaxial heat exchanger for deep boreholes. IOP Conf. Series: Materials Science and Engineering, 477(1), 012054. https://doi.org/10.1088/1757-899X/477/1/012054.

22. Soldo, E., \& Alimonti, C. (2015). From an Oilfield to a Geothermal One: Use of a Selection Matrix to Choose Between Two Extraction Technologies. In Proceedings World Geothermal Congress. Melbourne, Australia. 
23. Medhi, N., \& Das, M. (2018). A study on abandoned oil/gas wells as sustainable sources of geothermal energy. In International Conference on Renewable \& Alternate Energy (ICRAE2018). Guwahati, Assam, India. Assam.

24. Michaelides, E.E. (2012). Entropy production and optimization of geothermal power plants. Journal of Non-Equilibrium Thermodynamics, 37(3), 233-246. https://doi.org/10.1515/jnetdy2011-0024

25. Sircar, A., Yadav, K., \& Sahajpal, S. (2016). Overview on Direct Applications of Geothermal Energy. International Advanced Research Journal in Science, Engineering and Technology, 3(9), 128-137. https://doi.org/10.17148/IARJSET.2016.3925

26. Scafidia, J., \& Gilfillana, S. M. V. (2018). The feasibility of the "all-in-one" concept in the UK North Sea: offsetting carbon capture and storage costs with methane and geothermal energy coproduction in a depleted hydrocarbon field. In 14th International Conference on Greenhouse Gas Control Technologies. Melbourne, Australia.

27. Liu, J., Wang, F., Cai, W., Wang, Z., Wei, Q., \& Deng, J. (2019). Numerical study on the effects of design parameters on the heat transfer performance of coaxial deep borehole heat exchanger. International Journal of Energy Research, 43(12), 6337-6352. https://doi.org/10.1002/er.4357

28. Røksland, M., Basmoen, T. A., \& Sui, D. (2017). Geothermal energy extraction from abandoned wells. Energy Procedia, (105), 244-249. https://doi.org/10.1016/j.egypro.2017.03.309

29. Ziabakhsh-Ganji, Z., Nick, H.M., Donselaar, M.E., \& Bruhn, D.F. (2018). Synergy potential for oil and geothermal energy exploitation. Applied Energy, (212), 1433-1447. https://doi.org/10.1016/j.apenergy.2017.12.113

30. Zhu, Y., Li, K., Liu, C., \& Mgijimi, M. B. (2019). Geothermal Power Production from Abandoned Oil Reservoirs Using In Situ Combustion Technology. Energies, 12(23), 4476. https://doi.org/10.3390/en12234476

31. Zhang, L., Deng, Z., Zhang, K., Long, T., Desbordes, J. K., Sun, H., \& Yang, Y. (2019). WellPlacement Optimization in an Enhanced Geothermal System Based on the Fracture Continuum Method and 0-1 Programming. Energies, (12), 709. https://doi.org/10.3390/en12040709

32. Yildirim, N., Parmanto, S., \& Akkurt, G.G. (2019). Thermodynamic assessment of downhole heat exchangers for geothermal power generation. Renewable Energy, (141), 1080-1091. https://doi.org/10.1016/j.renene.2019.04.049

33. Song, X., Wang, G., Shi, Y., Zheng, R., \& Li, J. (2019). Numerical Analysis on Thermal Characteristics of an Open Loop Geothermal System in a Single Well. Energy Procedia, (158), 6112-6117. https://doi.org/10.1016/j.egypro.2019.01.501 